Bol. Soc. Bot. MÉxico 30:95-96 (1969)

\title{
EL PROYECTO INDEX NOMINUM GENERICORUM
}

\author{
Por IDA K. LANGMaN \\ MARY F. F. SOUTHWELL
}

En 1954, en el Congreso Internacional de Botánica en París, se reconoció definitivamente la importancia de preparar un índice de nombres genéricos, y se nombró un comité ejecutivo encargado de realizar los trámites necesarios para poner el programa en marcha. Este comité, formado bajo los auspicios de la International Association of Plant Taxonomists, constaba de los señores doc. tores J. Lanjouw, redactor general, A. A. Bullock y R. C. Collins, redactores con. sejeros, y F. A. Stafleu, redactor técnico.

La necesidad de preparar un índice de esta naturaleza había existido por muchos años. Por falta de tal índice se habían publicado en muchas ocasiones nombres ilegítimos homonímicos, dando lugar a la subsiguiente complicación de la literatura con cambios de nombres. Sin un índice de nombres, es preciso gastar mucho tiempo en revisar la literatura para evitar duplicaciones al proponer un nuevo nombre genérico.

El índice se presenta en forma de tarjetas impresas, del mismo tamaño de las tarjetas del Gray Card Index $\left(5 \times 12 \frac{1}{2} \mathrm{~cm}\right.$.). El primer grupo de 1000 tarjetas se publicó en octubre de 1955. Desde esa fecha se han publicado 22000 más, siempre en juegos de mil. Puesto que el Indice incluye no solamente nombres de plantas actuales, sino también plantas fósiles, y plantas de todos los grupos desde las bacterias hasta las espermatofitas, se calcula que el proyecto se encuentra más o menos a medio terminar.

Muchos botánicos de varias partes del mundo han aceptado la invitación del Comité Ejecutivo para colaborar en el proyecto, o han ofrecido sus servicios para ayudar en la obra. Entre ellos se encuentra un comité de consejeros de diez botánicos y cerca de setenta más que se han encargado de compilar y revisar los datos necesarios para las tarjetas. Para evitar errores es preciso, en cada caso, consultar la publicación original en la cual se haya descrito el nuevo género, igualmente que todas las publicaciones secundarias relacionadas con el nombre genérico: aquella en que se refiera a un sinónimo nomenclatural, la que incluya la descripción del basónimo etc.

En vista de que el proyecto se había prolongado mucho más de lo que se había pensado originalmente (cuando se esperaba terminar el proyecto en tres años), se hicieron gestiones ante la National Science Foundation de los Estados 
Unidos a fin de que esta organización aceptara la responsabilidad de proporcionar fondos suficientes para llevar a cabo el proyecto en unos 3 ó 4 años más.

En noviembre de 1965 se logró esto, y la Smithsonian Institution de Washington ofreció, por medio de su departamento de Botánica, espacio para una oficina en la cual se pudiera continuar la obra. Actualmente, dos personas se hacen cargo del trabajo bibliográfico del proyecto: la Sra. Ida K. Langman y la Sra. Mary F. Southwell. Dos otras personas sirven como ayudantes técnicos. La oficina superior queda en Utrecht, bajo la supervisión del Dr. Stafleu, y el Dr. J. J. Swart sigue, también en Utrecht, en el puesto de colaborador especial y redactor técnico, cargo que ha desempeñado durante los últimos años.

Se considera que el Indice será de gran utilidad para todos los institutos botánicos y herbarios donde se siguen investigaciones taxonómicas, tanto como para bibliotecas botánicas, jardines botánicos, estaciones de investigación y centros de investigación básica en agricultura y en universidades donde se presentan cursos de fitotaxonomía.

Quienes deseen más informes sobre el proyecto o sobre el procedimiento para obtener los juegos de tarjetas del Index Nominum Genericorum deberán dirigirse al Dr. F. A. Stafleu, International Bureau for Plant Taxonomy and Nomenclature, Lange Nietuwstraat 116, Utrecht, Netherlands.

Nota: Los datos preliminares con respecto al Proyecto Index Nominum Genericorum se publicaron en el informe de la Conferencia de Ginebra (Regnum Vegetabile 5:48, 1954) $y$ en Taxon $3: 213,1954$, y $4: 67,1955$. 